\title{
Assessing Lead Removal from Contaminated Water Using Solid Biomaterials: Charcoal, Coffee, Tea, Fishbone, and Caffeine
}

\author{
Lovell Agwaramgbo*, Nichole Lathan, Shelby Edwards, ShaKayla Nunez
}

Chemistry Department, Dillard University, New Orleans, USA.

Email: *lagwaramgbo@dillard.edu

Received April $8^{\text {th }}, 2013$; revised May $11^{\text {th }}, 2013$; accepted June $10^{\text {th }}, 2013$

Copyright (c) 2013 Lovell Agwaramgbo et al. This is an open access article distributed under the Creative Commons Attribution License, which permits unrestricted use, distribution, and reproduction in any medium, provided the original work is properly cited.

\begin{abstract}
Previous research has documented that solid biomaterials such as charcoal or waste coffee and tea have been used to remove heavy metals from contaminated aqueous solutions through adsorption. However, these studies used very low heavy metal concentrations between 10 to $100 \mathrm{ppm}$. Recently published research work reported that extracts of edible plants and fruits were able to effectively remove lead from contaminated aqueous solution. This paper evaluates the ability of charcoal, un-brewed coffee and tea, fishbone, and caffeine to remove lead from contaminated aqueous solutions. The order of lead removal from $1300 \mathrm{ppm}$ of lead solution is Charcoal (100\%) > Tea (97\%) > Coffee Ground $(88 \%)>$ Instant Coffee (83.5\%) > Coffee Bean (82\%) > Fishbone (76\%) > Caffeine (1.3\%). These results clearly demonstrate that not all solid biomaterials can adsorb lead and that caffeine, a component of coffee and tea does not participate in the removal of lead from contaminated solutions. Furthermore, the results suggest that two possible processes may be involved in the reactions presented here: adsorption of lead by the solid substrates and precipitation of lead by the solubilized biochemical components of the substrates.
\end{abstract}

Keywords: Heavy Metals; Chemisorptions; Coffee; Lead; Fishbone; Phytoremediation

\section{Introduction}

The world is becoming a global village, thus heavy metal contamination in one region will inherently have global consequences [1-5]. Contamination of soil, water, and air by heavy metals, particularly lead, poses a detrimental threat to our environment, humans, animals, plants, and marine life. Lead uptake, transport, and accumulation by plants and animals as well as the potential for its propagation into the food chain exacerbate its toxic health effects. Lead pollution is a consequence of many human activities such as lead paint production [6], mining [7], agricultural fertilizers, insecticides and pesticides [8]. Studies have shown that there is a strong correlation between chronic lead exposure to children and impaired cognitive skills [9], intellectual impairment [10], reduced IQ [11], and mental retardation [12]. Similarly, chronic lead exposure to adults has been linked to damage to the neurological, reproductive, central nervous and renal systems respectively [13-15]. Thus, removal of lead from

${ }^{*}$ Corresponding author. water and soil will have positive and beneficial implications on the ecosystem, global economy, agriculture, and health. Currently, many technologies such as phytoremediation (extraction, stabilization, and volatilization) have emerged for the removal of lead from soil [16-22]. Until recently, only expensive and unsafe technologies such as electro-deposition [23] and chemical precipitation [24] were available for heavy metal removal from contaminated water. Emerging research has provided safe and cheap technologies for the remediation of heavy metal contaminated water. Such technologies include precipitation and biosorption using safe liquid substrates [25-27], adsorption using solid chemical and biological adsorbents such as Louisiana red clay and soil [25]. Modified clay [28,29], soil [30], seed powder [31], waste coffee and tea [32-34], maize tassels [35], modified coconut fiber [36], and saw dust [37] have been used as adsorbents to remove heavy metals from contaminated water. However, most of these reported adsorption experiments with solid substrates were carried out at conditions that are not natural such as very low $\mathrm{pH}$, low heavy metal concentra- 
tions, and modified substrates. Therefore, the study reported here utilized natural solid substrates such as tea, coffee, fishbone, and spinach with out modification and at neutral $\mathrm{pH}$. The unnatural substrates (activated carbon and caffeine) used in this study were for comparison purposes.

\section{Materials \& Methods}

The lead nitrate, charcoal, and caffeine were purchased from Aldrich Chemicals and were used without further purification. Community Red Rose instant coffee, coffee ground, and coffee bean were bought from a local WalMart store. The coffee bean was ground in the store using store provided grinding machine.

\subsection{Preparation of Lead Nitrate Solution 1300 ppm}

Using an analytical balance, $1.3 \mathrm{~g}$ of lead Nitrate from Fisher Scientific (L6200) was dissolved in enough deionized water (added incrementally) to give $1000 \mathrm{ml}$ of solution. Then a stirring bar was dropped into the volumetric flask and the mixture was stirred until all the lead was completely dissolved. The flask was wrapped with aluminum foil to avoid much exposure to light while the solution continued to stir at room temperature until it was used.

\subsection{Preparation of Charcoal and Caffeine Solid Substrates}

Three $50 \mathrm{ml}$ centrifuge tubes were charged with $4.0 \mathrm{~g}$ of charcoal and labeled CC-S. Similarly, three other tubes were each filled with $4.0 \mathrm{~g}$ of caffeine and labeled CAFS.

\subsection{Preparation of Coffee and Tea Solid Substrates}

Separate triplicate 4.0 g samples of Lipton Tea and Community Dark Roast instant coffee, coffee ground, and coffee bean were respectively weighed out and placed in their respective $50 \mathrm{ml}$ centrifuge tubes labeled TEA-S, IC-S, CG-S, and CB-S.

\subsection{Preparation of Stock Fish Bone Substrate}

Six-2ft dried stockfish from Norway were bought from a local market, deboned after soaking in water at room temperature for $3 \mathrm{hr}$. The bones were washed with deionized water and dried in an oven at $50^{\circ} \mathrm{C}$ for $24 \mathrm{hr}$. The dried bones were pulverized using a blender. Three 50$\mathrm{ml}$ centrifuge tubes were charged with $4.0 \mathrm{~g}$ of the fishbone respectively. The tubes were labeled FB-S.

\section{Reaction of the Substrates with Lead}

Into each of the respective triplicate centrifuge tubes containing the substrates was added $50 \mathrm{ml}$ of $1300 \mathrm{ppm}$ of lead nitrate solution prepared above. The tubes and their contents were vortexed, secured tightly on a heavy duty Eberbach 6000 shaker, and agitated for $48 \mathrm{hr}$ at room temperature.

\section{Sample Preparation and Analysis}

\subsection{Sample Preparation}

After $48 \mathrm{hr}$, the shaker was stopped and the centrifuge tubes and their contents were centrifuged at $3000 \mathrm{rpm}$ for ten minutes. The resulting supernatant in each tube was transferred into another labeled clean centrifuge tube. All the labeled centrifuge tubes with their liquid contents were sent to PACE Analytical Services, Inc for lead analysis using EPA method 6010. Note that PACE Analytical Services, Inc is a commercial environmental laboratory that is accredited in accordance to the National Environmental Laboratory Accreditation Conference (NELAC).

\subsection{Sample Analysis for Lead after Reaction}

After the reaction period, the lead concentration (in ppm) in the liquid from each reaction tube was analyzed using EPA Method 6010 (Inductively Coupled Plasma-Atomic Emission Spectrometry (ICP-AES)).

\section{Results}

Data on Table 1 show residual lead in ppm in each reaction tube after contaminated water was treated with each solid substrate for $48 \mathrm{hr}$ and the percent of lead removed relative to the control: CTR $(1280,0 \%)$; CC-S $(0,100 \%)$, IC-S (212, 83\%), CB-S (226, 82\%), CG-S (151, 88\%), Tea-S (44, 97\%), FB-S (298, 77\%) CAF-S (1263, 1\%). Figures 1 and 2 show the amount of lead remaining in the reaction mixture after charcoal, coffee, tea, fish bone and caffeine solids were agitated with lead solution and the percent of lead removed, respectively.

In another but related experiment, each of a triplicate 5 g sample of ground salmon fish bone was mixed with 50 $\mathrm{ml}$ of $1000 \mathrm{ppm}$ lead solution for $48 \mathrm{hr}$ at room temperature on a shaker. The results in Figure $\mathbf{3}$ below suggest that salmon fishbone removed over $90 \%$ of the lead from contaminated water.

\section{Discussions}

The results on Table $\mathbf{1}$ and Figures $\mathbf{1}$ and $\mathbf{2}$ showed that the solid substrates except caffeine removed over $70 \%$ of the lead from contaminated water. 
Table 1: Residual \& removed lead in contaminated water after treatment with solid charcoal, coffee, tea, fishbone, and caffeine.

\begin{tabular}{ccccc}
\hline Sample & $\begin{array}{c}{[\mathbf{P b}] \text { in }} \\
\text { PPM }\end{array}$ & $\begin{array}{c}\text { Std. } \\
\text { Dev. }\end{array}$ & Std. Err. $\begin{array}{c}\text { \% Lead } \\
\text { Removed }\end{array}$ \\
\hline Control (Ctr.) & 1280 & 1632 & 9.42 & 0 \\
Charcoal (CC-S) & 0 & 0 & 0 & 100 \\
Instant Coffee (IC-S) & 211 & 24 & 14 & 83.5 \\
Coffee Bean (CB-S) & 225 & 10 & 6 & 82.4 \\
Coffee Ground (CG-S) & 151 & 7 & 4 & 88 \\
Tea (Tea-S) & 44 & 2.6 & 1.5 & 97 \\
Fish Bone (FB-S) & 298 & 13.5 & 8 & 77 \\
Caffeine (CAF-S) & 1263 & 41 & 24 & 1 \\
\hline
\end{tabular}

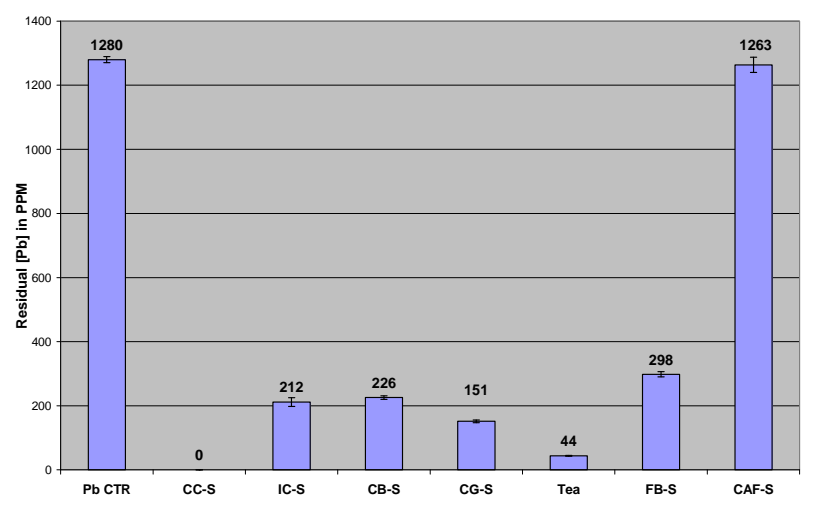

Figure 1. Residual lead concentration after contaminated water was treated with solid charcoal, coffee, tea, fish bone, and caffeine.

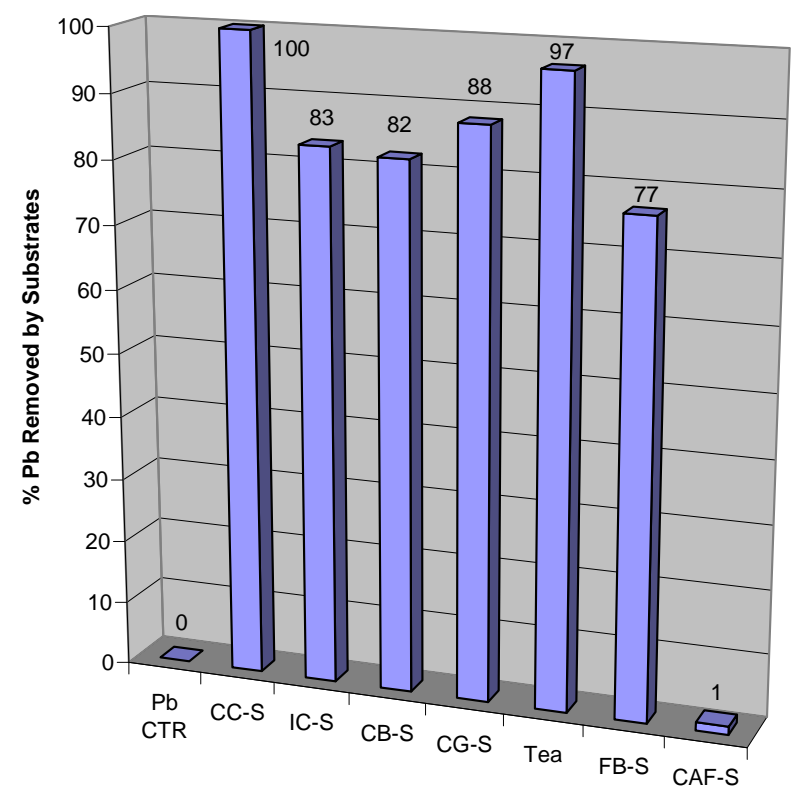

Figure 2. Percent Lead removed after contaminated water was treated with solid charcoal, coffee, tea, fish bone, and caffeine.

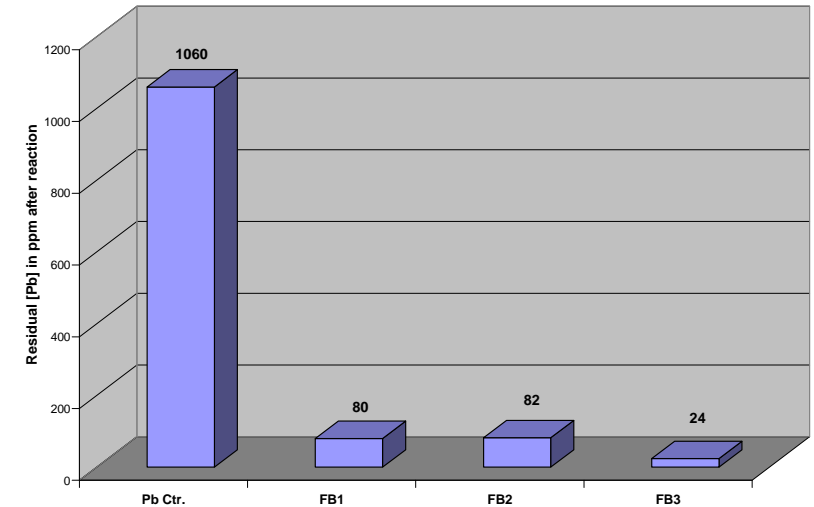

Figure 3. Residual Lead concentration after contaminated water was treated with salmon fish bone compared to 1000 ppm lead control.

Table 1 and Figures 1 and 2 clearly suggest that with the exception of caffeine, all the solid substrates (charcoal, tea, coffee ground, instant coffee, coffee bean and fishbone) have great ability to remove lead from contaminated water.

\section{Conclusion}

Solid charcoal, tea, coffee ground, instant coffee, coffee bean and fishbone were all able to remove from $70 \%$ $100 \%$ of lead from contaminated water. When the results of lead removal by solid coffee and tea are compared to those of aqueous extracts, it appears that a different mechanism is occurring for lead removal by the solid substrates and by the liquid extracts. Thus the results suggest that in the reaction of lead solution with solid substrates, adsorption is the predominant mechanism for lead removal while with liquid extracts, precipitation predominates. Caffeine did not remove lead from contaminated water in any appreciable amount $(1 \%$ lead removed). This suggests that caffeine is neither lead adsorbing nor lead precipitating agent.

\section{REFERENCES}

[1] S. Tong, Y. E. von Schirnding and T. Prapamontol, "Environmental Lead Exposure: A Public Health Problem of Global Dimensions," Bulletin of the World Health Organization, Vol. 78, No. 9, 2000, pp. 1068-1077.

[2] P. A. Meyer, M. J. Brown and H. Falk, "Global Approach to Reducing Lead Exposure and Poisoning," Mutation Research, Vol. 659, No. 1-2, 2008, pp. 166-175. doi:10.1016/j.mrrev.2008.03.003

[3] L. J. Fewtrell, A. Pruss-Ustun, P. Landrigan and J. L. Ayuso-Mateos, "Estimating the Global Burden of Disease Of Mild Mental Retardation And cardiovascular diseases from Environmental Lead Exposure,” Environmental Research, Vol. 94, No. 2, 2004, pp. 120-133. doi:10.1016/S0013-9351(03)00132-4 
[4] U. Forstner, "Land Contamination by Metals: Global Scope and Magnitude of Problem,” In: H. E. Allen, C. P. Huang, G. W. Bailey and A. R. Bowers, Eds., Metal Speciation and Contamination of Soil, CRC Press, Boca Raton, 1995, p. 133.

[5] D. A. Peel, "Environment Research: Is Lead Pollution of the Atmosphere a Global Problem?” Nature, Vol. 323, 1986, p. 200. doi:10.1038/323200a0

[6] H. W. Mielke, "Lead Dust Contaminated USA Communities, Comparison of Louisiana and Minnesota,” Applied Geochemistry, Vol. 8, Suppl. 2, 1993, pp. 257-261.

[7] J. Cotter-Howells and I. Thornton, "Sources and Pathways of Environmental Lead to Children in a Derbyshire Mining Village," Environmental Geochemistry and Health, Vol. 13, No. 2, 1991, pp. 127-135.

[8] Q. Y. Ma, T. J. Logan and S. J. Traina, "Lead Immobilization from Aqueous Solutions and Contaminated Soils Using Phosphate Rocks,” Environmental Science \& Technology, Vol. 29, 1995, pp. 1118-1126.

[9] S. Tong, "Lead Exposure and Cognitive Development: Persistence and a Dynamic Pattern,” Journal of Pediatrics and Child Health, Vol. 34, 1998, pp. 114-118.

[10] R. L. Canfield, C. R. Henderson Jr., D. A. Cory-Slechta, C. Cox, T. A. Jusko and B. P. Lanphear, "Intellectual Impairment in Children with Blood Lead Concentrations below $10 \mu \mathrm{g}$ Per Deciliter,” The New England Journal of Medicine, Vol. 348, 2003, pp. 1517-1526. doi:10.1056/NEJMoa022848

[11] M. L. Miranda, K. Dohyeong, M. A. Galeano, C. J. Paul and A. P. Hull, "Morgan, S. P. The Relationship between Early Child Hood Blood Lead Levels and Performance on End-of-Grade Tests,” Environmental Health Perspectives, Vol. 115, 2007, pp. 1242-1247.

[12] R. Nevin, "Trends in Preschool Lead Exposure, Mental Retardation, and Scholastic Achievement: Association or Causation?” Environmental Research, Vol. 109, No. 3, 2009, pp. 301-310. doi:10.1016/j.envres.2008.12.003

[13] H. Needleman, C. McFarland, R. Ness, S. Fienberg and M. Tobin, "Bone Lead Levels in Adjudicated Delinquents. A Case Control Study,” Neurotoxicology and Teratology, Vol. 24, 2003, pp. 711-717.

[14] R. A. Shih, H. Hu, M. G. Weisskopf and B. S. Schwartz, "Cumulative Lead Dose and Cognitive Function in Adults. A Review of Studies that Measured both Blood Lead and Bone Lead," Environmental Health Perspectives, Vol. 115, 2007, pp. 483-492.

[15] J. L. Lin, D. T. Lin-Tan, K. H. Hsu and C. C. Yu, "Environmental Lead Exposure and Progression of Chronic Renal Diseases in Patients without Diabetes," New England Journal of Medicine, Vol. 348, 2003, pp. 277-286.

[16] M. I. Lone, Z.-L. He, P. J. Stopffella and X.-E. Yang, "Phytoremediationof Heavymetal Polluted Soils and Water: Progresses and Perspectives," Journal of Zhejiang University Science B, Vol. 9, No. 3, 2008, pp. 210-220. doi:10.1631/jzus.B0710633

[17] R. L. Chaney, M. Malik, Y. M. Li, S. L. Brown, E. P. Brewer, J. Scott-Angle and A. J. M. Baker, "Phytoreme- diation of Soil Metals," Current Opinion in Biotechnology, Vol. 8, No. 3, 1997, pp. 279-284. doi:10.1016/S0958-1669(97)80004-3

[18] D. E. Salt, M. Blaylock, P. B. A. N. Kumar, V. Dushenkov, B. D. Ensley, L. Chet and L. Raskin, "Phytoremediation: A Novel Strategy for the Removal of Toxic Metals from the Environment Using Plants," Biotechnology, Vol. 13, No. 5, 1995, pp. 468-474. doi:10.1038/nbt0595-468

[19] P. B. A. N. Kumar, V. Dushenkov, H. Motto and I. Raskin, "Phytoextraction: The Use of Plants to Remove Heavy Metal from Soils," Environmental Science \& Technology, Vol. 29, 1995, pp. 1232-1238.

[20] M. M. Lasat, "Phytoextraction of Toxic Metals: A Review of Biological Mechanisms," Journal of Environmental Quality, Vol. 31, 2002, pp. 109-120. doi:10.2134/jeq2002.0109

[21] M. Sihl, M. A. Hajabbasi and H. Shareatmadari, "Heavy Metal Extraction Potential of Sunflower (Helliantus annus) and Canola Brassica napus," Caspian Journal of Environmental Sciences, Vol. 3, No. 1, 2005, pp. 35-42.

[22] R. D. Reeves, "Tropical Hyper-Accumulators of Metals and Their Potential for Phytoextraction," Plant Soil, Vol. 249, No. 1, 2003, pp. 57-65. doi:10.1023/A:1022572517197

[23] R. D. Armstrong, M. Todd, J. W. Atkinson and K. Scott, "Selective Electrodeposition of Metals from Simulated Waste Solutions," Journal of Applied Electrochemistry, Vol. 26, No. 4, 1996, pp. 379-384.

[24] T. R. Harper and N. W. Kinham, "Removal of Arsenic from Wastewater Using Chemical Precipitation Methods,” Water Environment Research, Vol. 64, No. 3, 1992, pp. 200-203. doi:10.2175/WER.64.3.2

[25] N. Lathan, S. Edwards, C. Thomas and L. Agwaramgbo, "Comparative Study of Lead Removal by Extracts of Spinach, Coffee, and Tea," Journal of Environmental Protection, Vol. 4, 2013, pp. 250-257. doi:10.4236/jep.2013.43029

[26] L. Agwaramgbo, C. Thomas, C. Grays, J. Small and T. Young, "An Evaluation of Edible Plant Extracts for the Phytoremediarion of Lead Contaminated Water," Journal of Environmental Protection, Vol. 3, No. 8, 2012, pp. 722-730. doi:10.4236/jep.2012.38086

[27] L. Agwaramgbo, E. Agwaramgbo, C. Mercadel, S. Edwards and E. Buckles, "Lead Remediation of Contaminated Water by Charcoal, LA Red Clay, Spinach, and Mustard Green,” Journal of Environmental Protection, Vol. 2, No. 9, 2011, pp. 1240-1244. doi:10.4236/jep.2011.29142

[28] P. Stathi, K. Litina, D. Gournis, T. S. Giannopoulos and Y. Deligiannakis, "Physicochemical Study of Novel Organoclay as Heavy Metal Ion Adsorbents for Environmental Remediation," Journal of Colloid and Interface Science, Vol. 316, 2007, pp. 298-309.

[29] S. P. Singh, L. Q. Ma and W. G. Harris, "Heavy Metal Interactions with Phosphate Clay: Sorption and Desorption Behavior," Journal of Environmental Quality, Vol. 
30, 2001, pp 1961-1968. doi:10.2134/jeq2001.1961

[30] E. F. Covelo, F. A Vega and M. L. Andrade, "Heavy Metal Adsorption and Desorption by a Eutric Regosol and a Distric Regosol," Geophysical Research Abstracts, Vol. 8, 2006, Article ID: 04553.

[31] l. M. Mataka, E. M. T. Henry, W. R. L. Masamba and S. M. Sajidu, "Lead Remediation of Contaminated Water Using Moringa stenopetala and Moringa oleifera Seed Powder," International Journal of Environmental Science and Technology, Vol. 3, No. 2, 2006, pp. 131-139. doi:10.1021/jf0496402

[32] M. Minamisawa, H. Minamisawa, S. Yoshida and N. Taka, "Adsorption Behavior of Heavy Metals on Biomaterials," Journal of Agricultural and Food Chemistry, Vol. 52, No. 18, 2004, pp. 5606-5611.

[33] S. S. Ahluwalia and D. Goyal, "Removal of Heavy Metals by Waste Tea Leaves," Engineering in Life Sciences, Vol. 5, No. 2, 2005, pp. 158-162.

[34] T. W. Tee and A. R. M. Khan, "Removal of Lead, Cad- mium, and zinc by Waste Tea Leaves," Environmental Technolgy Letters, Vol. 9, No. 11, 1988, pp. 1223-1232. doi:10.1080/09593338809384685

[35] C. M. Zvinowanda, J. O. Okonkwo, P. N. Shabalala and N. M. Agyei, "A Novel Adsorbent for Heavy Metal Remediation in Aqueous Environment," International Journal of Environmental Science and Technology, Vol. 6, No. 3, 2009, pp. 425-434.

[36] J. C. Igwe, A. A. Abia and C. A. Ibeh, "Adsorption Kinetics and Intraparticulate Diffusivities of $\mathrm{Hg}$, $\mathrm{As}$, and $\mathrm{Pb}$ Ions on Unmodified and Thiolated Coconut Fiber," International Journal of Environmental Science and Technology, Vol. 5, No. 1, 2008, pp. 83-92.

[37] M. Aliabadi, K. Morshedzadeh and H. Soheyli, "Removal of Hexavalent Chromium from Aqueous Solution by Lignocellulosic Solid Wastes," International Journal of Environmental Science and Technology, Vol. 3, No. 3, 2006, pp. 321-325. 